

DOSSlê: "Comunicação nas Periferias"

\title{
POR, PARA E DA COMUNIDADE: A CAMPANHA CONTRA O CORONAVÍRUS DO OBSERVATÓRIO DE FAVELAS
}

\author{
Daniella Guedes Rocha ${ }^{1}$
}

RESUMO: Partindo de discussões teóricas sobre comunicação comunitária, este artigo realiza a análise de conteúdo da campanha "Como se proteger do coronavírus", do Observatório de Favelas do Rio de Janeiro, a fim de identificar que elementos da comunicação comunitária são acionados nas narrativas visando a produzir mensagens que se aproximam do interlocutor, gerando assimilação da mensagem. O objetivo deste artigo consiste em compreender como a teoria sobre produção de conteúdo na comunicação comunitária se reflete no conteúdo produzido pelo Observatório, estritamente pensado para alcançar o propósito do movimento \#covid19nasfavelas, que seria o de conscientizar moradores sobre a prevenção à doença.

PALAVRAS-CHAVE: Favelas. Comunicação comunitária. Coronavírus.

ABSTRACT: Resumo : From theoretical discussions on community communication, this article analyzes the content of the campaign "How to protect yourself from the coronavirus", from the Observatório de Favelas do Rio de Janeiro, with the objective of understanding what elements are trggered in order to produce narratives that approach the interlocutor, generating assimilation of the message. The aim of this article is to understand how the theory of content production in community communication is reflected in the content produced by the Observatório, strictly designed to achieve the purpose of the \#covid19nasfavelas movement, which would be to raise awareness about disease prevention.

KEYWORDS: Favelas. Community Communication. Coronavirus.

\footnotetext{
${ }^{1}$ Bacharel em Comunicação Social - Jornalismo (UERJ), Mestre em Estudos Populacionais e Pesquisas Sociais (ENCE/IBGE) e Doutora em História, Política e Bens Culturais (CPDOC/FGV). Atualmente, é pesquisadora associada do Grupo Casa (IESP/UERJ). E-mail: guedes.dani@gmail.com
}

Revista AL TERJOR

Grupo de Estudos Alterjor: Jornalismo Popular e Alternativo (ECA-USP)

Ano 10 Volume ol Edição 23 Janeiro-Julho de 202l

Avenida Professor Lúcio Martins Rodrig̉ues, 443, Cidade Universitária, São Paulo, CEP: 05508-020 


\section{INTRODUÇÃO}

Desde o anúncio do primeiro caso de infecção pelo novo coronavírus no Brasil, em 26 de fevereiro de 2020, surgiu uma preocupação em relação ao contágio nas favelas e periferias do país. Se inicialmente o vírus atingiu as classes mais altas, era questão de tempo para chegar aos territórios ocupados pelas classes mais pobres, nos quais as condições locais, em tese, dificultariam as ações de prevenção à doença, denominada COVID-19. Tendo como principal orientação para prevenir o contágio pelo coronavírus a lavagem das mãos com água e sabão, havia dúvidas sobre como conseguir esse objetivo em locais sem água corrente ou sem distribuição oficial de água, com cidadãos sem renda para comprar itens básicos de higiene. Se o isolamento social passou a ser essencial para reduzir o contágio, como seguir essa orientação em áreas com alto adensamento habitacional, com famílias coabitando pequenas moradias? E com discursos divergentes até mesmo na esfera federal, além da grande circulação de fake news, como orientar a população sobre a prevenção contra o coronavírus? Entre as campanhas solidárias às favelas, com arrecadação de itens de higiene e alimentos, surgiram campanhas de comunicação, tendo como principal objetivo levar às populações das favelas e periferias informações sobre a doença. A campanha \#covid19nasfavelas e \#covid19nasperiferias invadiu as redes sociais, atrelada a ações de comunicação no território, como a instalação de faixas e uso de carros de som, entre outros.

Ser produzida da comunidade para a comunidade é uma das características presentes na conceituação de comunicação comunitária, assim como o caráter pedagógico e educativo e a realidade social presente na narrativa. Tendo como foco a análise de conteúdo da campanha de comunicação "Como se proteger do coronavírus", elaborada pelo Observatório de Favelas do Rio de Janeiro, este artigo pretende compreender de que modo ter a produção de conteúdo liderada por moradores de favelas e periferias, falando diretamente a este mesmo público, com elementos que se originam na realidade social destes locais pode resultar em materiais que se aproximam 


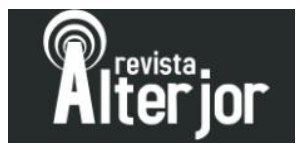

do interlocutor, gerando assimilação da mensagem, e principalmente de uma mensagem que se propõe de conscientização na prevenção a uma doença. Partindo de discussões teóricas sobre comunicação comunitária, mas sem se aprofundar em conflitos, ambivalências e tensões próprias deste tipo de comunicação, este estudo analisou 80 conteúdos, publicados no decorrer de 30 dias. A análise se focou em identificar que elementos da comunicação comunitária foram acionados nas narrativas com o objetivo de produzir mensagens que atinjam com eficácia o público ao qual se destina. $\mathrm{O}$ objetivo deste artigo consiste em compreender se a teoria sobre produção de conteúdo na comunicação comunitária possui reflexo no conteúdo produzido pelo Observatório de Favelas, estritamente pensado para alcançar o propósito do movimento \#covid19nasfavelas, que seria o de conscientizar moradores sobre a prevenção à doença - no fim, salvar vidas.

\section{A comunidade comunica}

Neste artigo, assumiremos a comunicação comunitária como também denominada popular, alternativa ou participativa, como faz Peruzzo (2009:56), caracterizando-se por processos baseados em princípios públicos, como "não ter fins lucrativos, propiciar a participação ativa da população, ter - preferencialmente propriedade coletiva e difundir conteúdos com a finalidade de desenvolver a educação, a cultura e ampliar a cidadania". Mesmo que possa ser entendida de várias formas, a comunicação comunitária denota uma comunicação que tem o povo como "protagonista principal e como destinatário" (idem, p.55). Zart (2019) considera que "do povo, pelo povo e para o povo" é uma "síntese próxima ao ideal utópico da Comunicação popular", enquanto que Campos (2006, apud SEQUEIRA \& BICUDO, 2007:8-9) afirma categoricamente que jornalismo comunitário é "uma atividade de comunicação originada na comunidade, administrada pela comunidade e dirigida à comunidade".

Como ressalta Zart (2019:41), é uma produção que "inverte a lógica", pois "privilegia a participação direta do público, com seus representantes, para fazer valer a discussão de suas pautas". O público deixa de ser "mero depositário de informações 




escolhidas e traduzidas por um grupo de iluminados e esclarecidos, e passa, democraticamente, a ser encarado como cidadão protagonista, ativo, pensante e atuante" (idem, p. 10). Esta transformação se intensifica com o desenvolvimento e disseminação das Novas Tecnologias da Informação e Comunicação (NTIC), que dotam a audiência de um inédito poder de comunicação. De uma "comunicação dirigida a pequenos grupos e centrada nos aspectos combativos dos movimentos populares", a comunicação comunitária ou popular passa a ampliar seu alcance, incorporando novos conteúdos e linguagens e desenvolvendo atividades de forma mais profissional (PERUZZO, 2009:50), incorporando as NTIC com todas as suas potencialidades, sem, no entanto, eliminar os formatos mais tradicionais, como o alto-falante e bicicleta ou carro de som.

A comunicação comunitária também se caracteriza por ser um instrumento de mobilização social. Baroni, Aguiar e Rodrigues (2011:315) ressaltam que o "jornalismo público" é construído através de "processos que ajudem as pessoas a identificar, avaliar e buscar soluções para os seus problemas cotidianos", ou formar cidadãos capazes de "buscar diferentes caminhos para a solução de problemas práticos de suas vidas em comunidade". Paiva e Sodré (2003) afirmam que, a curto prazo, a informação comunitária é balizada "pela geração de material informativo debruçado sobre aspectos muito próximos da vida quotidiana das pessoas". A longo prazo, "os veículos dispõemse a intervir formativamente, possibilitando um novo olhar sobre a realidade daqueles que representa". Neste sentido, Peruzzo (2006, apud Zart 2019) considera a "comunicação popular e alternativa" um processo "democrático e educativo", pois possui um "conteúdo crítico-emancipador e reivindicativo", buscando-se melhores condições de vida para as comunidades.

Sequeira e Bicudo (2007:9), após realizar um resgate teórico, afirmam identificar pelo menos "cinco características marcadoras do jornalismo comunitário", que garantem sua "personalidade, autenticidade e registros muito nítidos de uma carga genética exclusiva”. São elas:

a) valorização da realidade local; b) participação da comunidade durante todo o processo de produção; c) consagração das ideias da mobilização e da transformação; d) resgate de um viés pedagógico e educativo; e) articulação com a produção independente e de resistência (SEQUEIRA \& BICUDO, 2007:9). 




Mas que realidade local seria essa? Martino (2014) destaca que a compreensão da realidade deriva de conceitos compartilhados por várias pessoas, constituindo uma trama de significados compreendidos como uma realidade social.

O que garante a existência de uma realidade além dos meus sentidos e interpretações é a
existência de outros indivíduos a partir dos quais pode-se compreender a mesma
realidade. A realidade não é uma alucinação minha por conta do reconhecimento dos
mesmos elementos, objetos, fatos e significados por outras pessoas além de mim. Esse
reconhecimento mútuo dos significados, essa atribuição dos mesmos sentidos e
significações às coisas é garantia da existência de algo além de mim, de uma realidade
considerada comum, normal e aceitável por outros indivíduos. Em outras palavras, uma
realidade social (MARTINO, 2014:81).

Ao acompanhar a I Virada Comunicação, evento realizado em 2017 pela Rede Jornalistas das Periferias, Martini (2018:54) afirma que o entendimento entre os participantes era de que o diferencial do jornalismo periférico se baseia em que as narrativas são elaboradas a partir de um determinado território, o que as diferencia por “conterem perspectivas específicas, que não podem ser entendidas fora dessa relação com o lugar de pertencimento dos sujeitos representados nas histórias e dos sujeitos produtores da comunicação”. Ao analisar a página Maré Vive, Medrado (2019:183) ressalta que a página adota o jornalismo comunitário "à medida em que trabalha com problemas que são específicos da Maré", ou seja, que são de interesse da comunidade, mas que "também se relacionam com questões sociais brasileiras e globais mais amplas, como desigualdade social, racismo e violência policial".

Chagas (2009), quando reflete sobre jornalismo cidadão e comunicação comunitária, afirma que a diferença entre os dois conceitos seria uma questão de número, já que a comunicação comunitária seria uma experiência de grupo, enquanto o cidadão-jornalista "exerce, em certo sentido, uma ação individual". No jornalismo cidadão, cada cidadão é um repórter - “o cidadão é o próprio meio". No entanto, "se é cidadão, o cidadão-jornalista está circunscrito a algum lugar, um lugar-cidade, sem o qual ele é incapaz de reconhecer-se cidadão”. Neste caso, o cidadão-jornalista é cidadão de algum lugar - "não se trata de buscar meramente atrelar o cidadão-jornalista a uma localidade física, mas de evidenciar o caráter imaginário da comunidade a que pertence" (CHAGAS, 2009:73). A comunidade não se detém ao aspecto territorial. Zart (2009), ao citar R. M. MacIver \& C. Page, considera que comunidade seria a partilha "não deste ou 


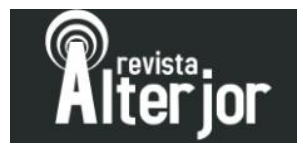

daquele interesse, mas das condições básicas de uma vida em comum”; compreende, entre outros aspectos, cultura e objetivos comuns, "identidade natural e espontânea" entre seus membros, sentimento de pertencimento e linguagem comum.

Esta comunidade acaba por produzir narrativas locais, relacionadas com a realidade social da mesma. Holmes (2009) usa a definição de Ballantyne (2002:2) para se referir a conteúdo local, como "the expression of the locally owned and adapted knowledge of a community - where the community is defined by its location, culture, language, or area of interest”. Um conteúdo elaborado por grupos locais, com mensagens e informações locais relevantes, e que possibilita oportunidades de interação e comunicação entre os moradores, expressando "suas próprias ideias, conhecimento e cultura". Para a autora, "connecting content to the multiple sites of its production, reception and (re)interpretation implies then that local content is more than a text, and can also be thought of as practice" (HOLMES, 2009). Uma prática cujo discurso produzido, para Martino (2014), carrega as "marcas de sua produção": o modo de falar de cada indivíduo é fruto da "realidade material das relações sociais". Ou seja, "cada grupo social, por conta de sua prática cotidiana, carrega em si um grupo particular de palavras, signos, significados, expressões" (MARTINO, 2014:125), ou um modo de pensar a partir dessas palavras que formará o discurso específico desse grupo.

\section{\#covid19nasfavelas}

O Observatório de Favelas, com sede na Maré, surgiu em 2001, como um programa do Instituto de Estudos do Trabalho e Sociedade (IETS), com atividades nos eixos pesquisa e formação, com o intuito de contribuir para "a ruptura com a visão dominante" que associa as comunidades "prioritariamente à violência, à criminalidade e à pobreza" (ALVES, 2014). Em 2003, o Observatório se constituiu como uma entidade autônoma e atualmente atua em cinco frentes, sendo uma delas a Comunicação, em que o Observatório se propõe a "elaborar conceitos, produzir informações e representações que ponham em perspectiva visões estereotipadas e homogeneizantes sobre as favelas e espaços populares”. Para Alves (2014:163), o Observatório defende uma comunicação 


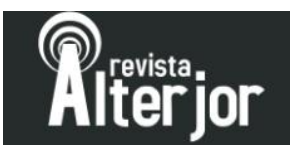

que leve em conta a "multiplicidade de demandas políticas, manifestações culturais e processos de produção subjetiva encontrados nos territórios populares", com o objetivo de "intervir na disputa pela construção de novos imaginários sobre a cidade".

Com histórico de luta e ativismo nas favelas cariocas, a instituição não deixaria de se associar à campanha de prevenção ao coronavírus que se caracterizou pelas hashtags \#covid19nasfavelas e \#covid19nasperiferias nas redes sociais. Com o avanço do contágio pelo novo coronavírus no Rio de Janeiro e o aumento da preocupação com a vida de moradores de favelas e periferias, diversos institutos e organizações sociais que atuam nestes territórios lançaram a campanha, que se caracterizou por pensar em soluções de cuidado e prevenção ao novo coronavírus nas favelas e periferias, não só com ações de comunicação mas também com arrecadação de alimentos e produtos de higiene e limpeza para serem distribuídos a moradores de diversas localidades. $\mathrm{O}$ objetivo principal da campanha consistia em frear o contágio e evitar a sobrecarga do sistema público de saúde. Além da campanha nas redes sociais, ações de comunicação no território incluíram a impressão de milhares de cartazes, elaboração de faixas a serem penduradas nas ruas e contratação de carros de som para levar mensagens de conscientização aos moradores, entre outras.

A campanha "Como se proteger do coronavírus", do Observatório de Favelas, se insere neste movimento. A partir de consulta a especialistas, foram produzidos áudios, vídeos e peças gráficas, que poderiam vir a ser um cartaz, um banner digital, uma imagem a ser compartilhada. As redes sociais foram o canal escolhido para a divulgação das peças: grupos de Whatsapp e os perfis do Observatório no Facebook, Twitter, Instagram e Youtube. A instituição afirma que os materiais chegavam diariamente a 5 mil pessoas, entre listas de contato e interações nas redes sociais, mas há uma projeção de alcance maior, já que não se consegue mensurar o compartilhamento nas redes dessas pessoas atingidas diretamente. Priscila Rodrigues, coordenadora de Comunicação do Observatório de Favelas, afirma que o "Observatório se propôs a incidir pública e politicamente por meio da comunicação, costurando narrativas de proteção, enfrentamento e cuidado pensadas para e a partir de moradoras/es de favelas e periferias". 


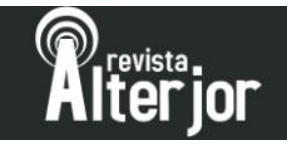

A partir de discussões teóricas sobre comunicação comunitária, a pesquisa aqui apresentada adotou como metodologia a análise de conteúdo dos materiais produzidos, tendo como objetivo identificar quais elementos que caracterizam a comunicação comunitária são acionados nas narrativas, visando a produzir mensagens que atinjam com eficácia o público ao qual se destina. Todo o conteúdo da campanha está reunido no endereço http://of.org.br/como-se-proteger-do-coronavirus/, com o intuito de facilitar o acesso aos materiais. Nesta pesquisa, foram analisados os textos e elementos gráficos dos trinta primeiros temas produzidos, publicados entre 19 de março e 18 de maio de 2020, sem uma periodicidade padronizada. Especialistas foram consultados em 24 temas, e outros seis foram produzidos com parceiros do Observatório. A maioria dos temas são desenvolvidos com o trio peça gráfica - áudio - vídeo, com algumas exceções. Ao todo, para este artigo foram analisados 34 peças gráficas, 20 vídeos e 26 áudios, cada um com duração média de 1’30". Os vídeos utilizam os áudios como off, acompanhados de cartelas com as principais mensagens e desenhos com traços simples que retratam as situações relatadas. Portanto, em termos de análise de conteúdo, a mensagem é a mesma nos áudios e vídeos, sem acréscimo de elementos relevantes. Neste caso, como opção metodológica, no texto será priorizada a citação aos áudios, publicados em maior número. A análise se focou principalmente nas escolhas lexicais presentes nos textos, identificando suas relações com o território e como são construídas com o objetivo de gerar identificação e engajamento junto ao destinatário da mensagem.

\section{Produção por, para e a partir de}

A campanha do Observatório de Favelas sobre o coronavírus possui características aqui apontadas nos conceitos de comunicação comunitária: produção de conteúdo por e para a comunidade com objetivo de educar e mobilizar os moradores acerca de uma pauta, utilizando elementos da realidade local na narrativa. Rodrigues (2020) afirma que uma "equipe majoritariamente feminina, jovem, preta e periférica" vinha se dedicando diariamente à elaboração da campanha, desde o início do isolamento social. Esta informação de que o material é produzido pelos colaboradores da instituição 




é colocada no início dos áudios e vídeos. Em todos os áudios, que também são os offs dos vídeos, os locutores se identificam através da sequência "Aqui quem fala é o ---, eu trabalho no Observatório de Favelas do Rio de Janeiro". Para nós, são nomes como Aruã, Carlão, Michele, Erika, Isabela, Thaís, Kita. Para os moradores da Maré, são pessoas conhecidas, seus vizinhos, profissionais encontrados nos locais de atendimento do Observatório, o que, de algum modo, aproxima o locutor da audiência. E mesmo que eu não conheça, saber que aquela pessoa que está me passando tal informação trabalha em uma instituição respeitada como o Observatório credencia o conteúdo como sendo verdadeiro, no qual devo acreditar, e vou parar para escutar. Esta é a intenção na produção "pela" comunidade, encontrada na conceituação de comunicação comunitária. E o processo não fica somente com os colaboradores do Observatório; no quarto dia de campanha, o material gráfico estimula a colaboração de todos na produção de conteúdo - "Manda sua dúvida pra cá! Se liga nos temas da semana". Além da colaboração na produção dos conteúdos, os moradores são convidados a atuar na divulgação e publicação dos materiais. O segundo material gráfico solicita: "Baixe os vídeos e use e abuse nos grupos de Whatsapp, feeds de Instagram e Facebook e stories!”. Já os áudios e vídeos se encerram com a mensagem "Então manda esse áudio para geral que você ama e quer cuidar em tempos de coronavírus", estimulando o compartilhamento dos materiais.

Porque se é produzida por, também é para a comunidade. Vinte dos 26 áudios possuem a expressão “Alô morador, alô moradora!", logo no início, chamando a atenção para o conteúdo. Depois da apresentação do locutor, aqui já comentada, os áudios seguem com "e a gente quer te dar um papo sobre" o tema do dia. O conteúdo é quase uma conversa direta com o morador. "Vocês, nossos queridos mais velhos, não podem circular nesse momento de alto risco de contaminação", afirmam o áudio e vídeo voltados para os idosos. "Hoje o papo é reto para vocês, que seguem trabalhando em tempos de coronavírus", fala o locutor para os mototaxistas. "Não é porque você que está de máscara que é 100\% seguro sair de casa. (...) E olha só, gente: importante, importantíssimo: tnt e perfex não são tecidos", ressalta a locutora sobre o uso de máscaras, em um recado direto, ou papo reto, aos moradores. 
O processo de conscientização que se inicia no processo colaborativo de produção se acentua na mensagem. No penúltimo dia, o áudio apresenta uma interpretação sobre como o vírus chegou às favelas e periferias. Com o tema “Coronavírus em números”, produzido pelo Eixo de Políticas Urbanas do Observatório de Favelas, a ideia principal é que a propagação veio dos bairros e regiões mais ricas para favelas e periferias, que por sua vez "reagem e ensinam!", através da mobilização e dos conteúdos educativos das campanhas colocadas em prática.

O coronavírus chegou ao Brasil nos bairros mais ricos das grandes cidades, onde vive a maioria das pessoas que viajam para fora ou que recebem em suas casas pessoas que circulam por outros países. Logo depois, ele se espalhou por outras regiões e cidades, mas ele não se move sozinho. As pessoas que precisam se deslocar entre as regiões mais ricas da cidade e as favelas e periferias, em geral para trabalhar, levam o vírus para suas casas e vizinhanças e aí a chegada dele nas favelas e periferias se torna um prato cheio para um bando de gente ficar doente ao mesmo tempo e com dificuldade de se recuperar, porque não há nesses territórios a mesma estrutura de saúde pública, de saneamento básico, moradia e água corrente, por exemplo.

A linguagem usada para explicar o que é o vírus é simplificada, com aproximação da realidade dos moradores: "O vírus é formado por uma gordurinha. Então, imagina aquela vasilha cheia de gordura que você tem em casa; que pra lavar, você usa detergente ou água quente. Então, com o vírus, é a mesma coisa”. A prevenção da doença, em si, é tratada diretamente em dois dias; logo no primeiro, os materiais se dedicam à importância da lavagem das mãos com água e sabão e o uso do álcool em gel. No dia 15, quando se fala sobre o uso das máscaras na proteção contra o COVID-19, o recado é claro: "Mas se liga: não é porque você que está de máscara que é 100\% seguro sair de casa".

O vírus chegou, é assim que funciona, desse modo que nos protegemos, mas e se eu estiver com a doença? No dia 21 , os materiais se dedicam a informar sobre os principais sintomas e motivos para ir ao hospital, ressaltando a importância de se saber previamente quando e onde buscar ajuda. O Boletim "De Olho no Corona", da Redes de Desenvolvimento da Maré, que mapeou as condições de equipamentos de saúde e os casos de COVID 19 no complexo, é citado no dia 28. As peças chamam a atenção para o fato de que a Maré possui mais de 140 mil moradores (Censo Maré/2019) e apenas uma Unidade de Pronto-Atendimento, na Vila do João, com 15 leitos hospitalares - 


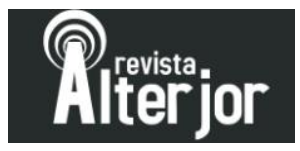

"Em dias normais, a gente já sabe que a UPA fica lotada, é muita gente. Imagina só na pandemia?". A preocupação com o "cuidado coletivo" também é citada, quando o Observatório ressalta que menos infectados significa mais leitos disponíveis - "Ajude o SUS!”. Assim, a ação individual visa à proteção do coletivo - "Nós por nós!".

Outro ponto a ser ressaltado na campanha é a relação com o território, que não só influencia a produção das narrativas como as caracteriza. O principal ponto que se destaca se relaciona com a necessidade de paralisação das atividades de lazer e culturais nas periferias por conta da pandemia. Momentos que possam gerar aglomerações, como churrascos, bailes funk, partidas de futebol, são citados em mais de um dia de campanha, demonstrando o quanto a cultura é importante no território, e que o afastamento dessas atividades, para a prevenção da doença, representaria uma ruptura no cotidiano, mas seria necessário na luta contra o coronavírus. No terceiro vídeo da campanha, "Isolamento e contaminação", o áudio é uma batida de funk, e a arte é semelhante a outra que circulou bastante nas redes sociais: um infográfico em que uma pessoa contamina várias outras, e dessas abrem outras setas indicando que outras pessoas são contaminadas a partir dessas, e assim por diante. Se tirarmos uma pessoa dessa cadeia, diminuímos a contaminação. As situações em que essas pessoas são retiradas da cadeia de contaminação, na campanha do Observatório, são próximas à realidade das periferias: "Essa pessoa foi liberada do trabalho. Essa pessoa não fez churrasco na laje. Essa pessoa não foi ao baile. Essa pessoa não foi ao campo jogar bola. Evite espalhar o vírus. Fique em casa”.

O banner digital do terceiro dia, com o tema "O vírus está em festa", cita "a feira, o baile e o churrasco na laje" como "prato cheio para proliferação [do vírus]". No dia 24, além do churrasco, a roda de pagode também é lembrada: "Nada de churras ou pagodeira. Assim, você só está ajudando a propagar mais a doença”. A ansiedade causada pelo isolamento social, com o consequente afastamento dos momentos culturais e de lazer, é citada no $18^{\circ}$ dia, em que se discute "Por que é importante ficar em casa?", com expressões de linguagem características: "A gente sabe que quem é de samba não vê a hora de se jogar numa roda de samba. Quem é de funk, só pensa em balançar a raba no baile. (...) Mas, gente, o assunto é sério". 


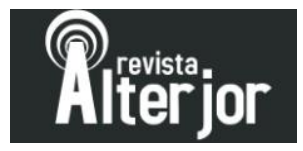

Outro ponto a ser destacado é a questão de que a moradia nas favelas e periferias ganha contornos particulares, muitas delas adensadas, sem ventilação, com poucos cômodos; algumas ainda em madeira, sem saneamento básico, sem ligação oficial de água ou de energia elétrica. Como fazer o isolamento de pessoas dos grupos de risco ou com sintomas em moradias com essas características? No dia 25, o áudio trata dessa questão: "é importante, se for possível, organizar a casa para o isolamento social e evitar ainda mais o contato com as outras pessoas, mesmo que isso pareça um desafio enorme porque a casa é pequena, só tem um quarto, só um banheiro, porque não é ventilada, e por aí vai". As principais orientações para uma melhor ventilação são janelas e portas abertas para o ar natural circular, ar-condicionado desligado, ventilador ligado de cima para baixo. Portas e janelas abertas, no entanto, não são convite para uma das atividades mais corriqueiras de uma vizinhança, a conversa na porta da casa. No áudio que fala sobre os cuidados a idosos, o recado é direto: "Ei, vizinha! Janelas e portas das casas das vovós abertas não são convite para entrar ou se aproximar". Voltando ao quarto vídeo, o locutor indica algumas ações que podem ser tomadas para aumentar a ventilação das casas que são possíveis apenas em barracos de madeira: "Se for possível, dá pra fazer buracos na parede com a ajuda da furadeira. Anota aí os lugares certinhos! 1: mais ou menos a 30 centímetros do piso. 2: na altura da janela, mais ou menos a 1,10m do chão, e 3: 20 centímetros abaixo do teto. Se ligou?". Dicas como essas não se enquadram em outras realidades que não em territórios onde ainda existem moradias construídas em madeira.

Outro ponto relacionado com a realidade social de favelas e periferias diz respeito à preocupação com profissionais que não puderam parar de trabalhar no período da pandemia, muitos deles moradores destes territórios. No segundo dia, a arte gráfica afirma "Hey, patroa! Hey, patrão! Libere a empregada", uma alusão a que muitas das empregadas domésticas não tinham sido liberadas, no início da pandemia, para ficarem em casa, continuando a se expor nos deslocamentos. A "galera que não pode parar" é lembrada no dia 18. Se quando a mídia hegemônica fala de profissionais da saúde lembra de médicos e enfermeiros, aqui se fala de "maqueiros, serviços gerais e recepcionistas", ou de "quem trabalha nos serviços essenciais, tipo mercado, 




transportes, farmácias, postos de abastecimento, coleta de lixo, e por aí vai”. O áudio afirma que "tem uma outra galera que a gente conhece bem, é nossa mãe, nosso tio, nossa amiga, nosso irmão, gente que trabalha na informalidade, vendendo, entregando, limpando...”. Os mototaxistas ganham um dia de campanha só para eles, no $10^{\circ}$ dia: "Hoje o papo é reto para vocês, que seguem trabalhando em tempos de coronavírus. Estamos aqui muito preocupados com vocês, uns dos maiores responsáveis pelo ritmo das favelas e periferias desse Brasil”.

Quanto ao discurso, como mais um elemento de aproximação com o público, na lógica de possibilitar que este se reconheça no conteúdo produzido, os materiais analisados possuem diversas expressões comumente utilizadas pelos moradores periféricos: "A gente quer te dar um papo"; "Passa o áudio para geral”; "Se ligou?"; "Qual foi?"; "Sem vacilação"; "Se liga no toque”; “evite o buzão lotado"; "Hoje o papo é reto"; "Copiou essa parte?"; "não vão fazer a M"; "Se liga nesse bafão!”; "Na real”; "Fala, cria! Aqui quem brota"; "a gente quer te passar a visão"; "Tá ligado?; "O caô tá brabo"; "junta o bonde"; "Seja parça"; "o bagulho está mesmo doido"; "serve pra geral"; "Sacou a diferença?"; "Pega a visão"; "Não dá pra vacilar"; "Bora lá?". Marcas do território na linguagem que irão compor a narrativa da campanha.

\section{Considerações finais}

Para Sequeira e Bicudo (2007:10), no jornalismo, a "narrativa precisa viabilizar estratégias capazes de criar vínculos, identidades e o sentimento do pertence", permitindo ao público afirmar "eu me reconheço nessa notícia, ela faz parte de meu cotidiano, ainda que não tenha acontecido aqui onde moro". Geralmente, a grande mídia, apesar do amplo alcance, não consegue "chegar falando a linguagem local, ela não sabe o nome das pessoas, ela não conhece os costumes”. A comunicação comunitária, ao possibilitar a construção de narrativas geradas e protagonizadas por moradores de favelas e periferias, circulando de si para si mesmos, seria capaz de gerar esta identificação dos interlocutores com as narrativas produzidas. A análise de conteúdo dos materiais da campanha do Observatório de Favelas contra o coronavírus 


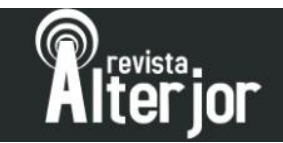

revelou o reflexo de alguns elementos presentes nos conceitos sobre comunicação comunitária nas narrativas, como a produção pela e para a comunidade, o caráter educativo e a valorização da realidade local.

Procurou-se demonstrar que, ao recorrer a estes elementos nas narrativas, a equipe do Observatório de Favelas recorre a preceitos teóricos da comunicação comunitária e busca se aproximar do público, gerando identificação, posterior atenção e assimilação do conteúdo. No entanto, não conseguimos mensurar se somente o uso destes elementos seriam suficientes para que a mensagem seja compreendida, para que o áudio seja ouvido até o final, para que o vídeo seja aberto no celular, para que a colaboração solicitada seja de fato realizada. Somente nos detivemos no conteúdo da campanha e nos esforços da instituição em produzir um conteúdo atraente para o interlocutor, uma vez que a campanha possui como objetivo o interesse público e o bem comum. O Observatório solicita o compartilhamento de informações como uma demonstração de cuidado com o coletivo, como resposta a uma realidade marcada pela falta de direitos fundamentais e ausência do poder público. Se conseguiu atingir seu propósito, a instituição ofereceu recursos para a sobrevivência, em meio a uma pandemia, em um território marcado pela desigualdade. Como afirma Rodrigues (2020), uma disputa coletiva por "narrativas de existência para e a partir de moradores de favelas e periferias".

\section{REFERÊNCIAS}

ALVES, Eduardo. Observatório de Favelas em diálogo com a sociedade. Entrevista concedida à Revista Interfaces. Entrevistadores: Bruno Moreira de Moraes, Izabel Antonina de Araújo Miranda e Robson Paulo dos Santos. Interfaces - Revista de Extensão da UFMG, Belo Horizonte, v. 2, n. 3 / jul.-dez. 2014, pp. 159-168.

BARONI, Alice; AGUIAR, Leonel; RODRIGUES, Felipe. "Novas configurações discursivas no jornalismo: narrativas digitais nas favelas do Rio de Janeiro". Estudos em Comunicação n ${ }^{\circ} 9$ / Maio de 2011, pp. 309-327. 


\section{Rि:eijor}

CHAGAS, Viktor. "Por que é Cidadão o Jornalista Cidadão?". Dissertação de Mestrado. Programa de Pós-Graduação em História, Política e Bens Culturais. Fundação Getúlio Vargas, 2009.

HOLMES, Tori. "Local content in Brazil: conceptual framework and methodological implications". In: E. ARDÈVOL, A. ROIG (coords.). Researching media through practices: an ethnographic approach [online dossier]. Digithum. Iss. 11, 2009.

MARTINI, Mara Rovida. "As periferias pelos periféricos: um fenômeno jornalístico contemporâneo". Revista Extraprensa, 12(1) / 2018, pp. 50-65.

MARTINO, Luís Mauro Sá. Teoria da comunicação: ideias, conceitos e métodos. Petrópolis, RJ: Vozes, 2014.

MEDRADO, Andrea Meyer. "Comunidade na cidade: mídias comunitárias como infraestruturas comunicacionais”. Eco-Pós, v. 22, n. 2 / 2019.

PAIVA, Raquel; SODRÉ, Muniz. O sequestro da fala comunitária. Rio de Janeiro: ECO-PÓS, 2003.

PERUZZO, C. M. K. “Conceitos de comunicação popular, alternativa e comunitária revisitados e as reelaborações no setor”. ECO-Pós, v.12, n.2 / Maio-agosto 2009, pp. 46-61.

RODRIGUES, Priscila. Disputando narrativas de existência. Disponível em: https://of.org.br/noticias-analises/disputando-narrativas-de-existencia/. Acesso em 28/07/ 2020.

SEQUEIRA, C.; BICUDO, F. "Jornalismo Comunitário: Conceitos, Importância e Desafios Contemporâneos". Intercom: Sociedade Brasileira de Estudos Interdisciplinares da Comunicação, XXX Congresso Brasileiro de Ciências da Comunicação: Santos, 2007.

ZART, Luiz Henrique. "Comunicação Popular: A narrativa jornalística por outras mãos”. In: Narrativas midiáticas contemporâneas: sujeitos, corpos e lugares [recurso eletrônico] / Organizadores: Demétrio de Azeredo Soster, Fabiana Piccinin - Santa Cruz do Sul: Catarse, 2019. 